\title{
Performance of the Finnish Diabetes Risk Score (FINDRISC) in the Identification of Dysglycemia in an Urban Population in Ouagadougou (Burkina Faso)
}

\author{
Solo Traoré1*, Boyo Constant Paré1, Désiré Lucien Dabourou², Oumar Guira1,3, \\ Yempabou Sagna4, Julie Patricia Kamouni1 ${ }^{1}$, Lassané Zoungrana1,3, Réné Bognounou ${ }^{3}$, \\ Hervé Tiéno ${ }^{1,5}$, Youssoufou Joseph Drabo1,3

\begin{abstract}
${ }^{1}$ Training and Research Unit in Health Sciences, Joseph Ki ZERBO University, Ouagadougou, Burkina Faso
${ }^{2}$ Institute for Research in Health Sciences/National Center for Scientific and Technical Research, Ouagadougou, Burkina Faso

${ }^{3}$ Department of Internal Medicine, Yalgado Ouedraogo Teaching Hospital, Ouagadougou, Burkina Faso

${ }^{4}$ Higher Institute of Health Sciences/Nazi BONI University, Bobo Dioulasso, Burkina Faso

${ }^{5}$ Department of Internal Medicine, Bogodogo Teaching Hospital, Ouagadougou, Burkina Faso

Email: ^fredotraore@yahoo.fr
\end{abstract}

How to cite this paper: Traoré, S., Paré, B.C., Dabourou, D.L., Guira, O., Sagna, Y., Kamouni, J.P., Zoungrana, L., Bognounou, R., Tiéno, H. and Drabo, Y.J. (2021) Performance of the Finnish Diabetes Risk Score (FINDRISC) in the Identification of Dysglycemia in an Urban Population in Ouagadougou (Burkina Faso). Open Journal of Internal Medicine, 11, 39-54.

https://doi.org/10.4236/ojim.2021.112003

Received: February 25, 2021

Accepted: April 6, 2021

Published: April 9, 2021

Copyright $\odot 2021$ by author(s) and Scientific Research Publishing Inc. This work is licensed under the Creative Commons Attribution International License (CC BY 4.0).

http://creativecommons.org/licenses/by/4.0/ (c) (i) Open Access

\begin{abstract}
Background: Diabetes mellitus is a real public health problem worldwide and is growing in developing countries. Our aim was to determine the prevalence of undiagnosed type 2 diabetes mellitus (T2DM) and to evaluate the performance of the Finnish Diabetes Risk Score (FINDRISC) questionnaire to identify type 2 diabetics in the urban population of Ouagadougou, Burkina Faso. Methodology: This was a cross-sectional study among volunteers aged 18 years and older recruited systematically from November 11 to 16, 2019, in the city of Ouagadougou, Burkina Faso, FINDRISC score was used. Analysis of the Receiver Operating Characteristic (ROC) curve was used to study the diagnostic performance of FINDRISC for the identification of type 2 diabetics. The optimal threshold was determined by the sum of the highest sensitivity and specificity. Multivariate logistic regression was used to analyze the association of each variable used in the calculation of the FINDRISC score. Results: A total of 1276 individuals were included in the analyses, of which 667 (52.27\%) were women. The average age was 34.16 years (SD: \pm 12.42 ). The prevalence of T2DM was $10.74 \%$. The mean FINDRISC score was 5.85 (SD: \pm 4.31 ). The majority $(58.54 \%)$ of individuals had a low risk of diabetes according to the FINDRISC score $0-7$, while $3.61 \%$ had a score $\geq 15$. The FINDRISC score showed good performance (AUC $=0.70$ ) in identifying undiagnosed type 2 diabetics. However, the variables in the score that best pre-
\end{abstract}


dicted the likelihood of being diabetic were age ( $\mathrm{p}<0.001)$, daily physical activity $(p=0.004)$, use of antihypertensive medication $(p=0.007)$ and waist circumference $(\mathrm{p}<0.001)$. The optimal cut-off score $\geq 7$ was the best predictor of the likelihood of having T2DM. Conclusion: The Finnish Risk Score (FINDRISC) is a good predictor of the risk of dysglycemia in Burkina Faso. It is a score to be promoted in daily clinical practice because it is easy to use, affordable and non-invasive. Further studies are needed to make modifications to the FINDRISC questionnaire in case it is applied to other ethnic groups.

\section{Keywords}

Identification, Diabetes Type 2, FINDRISC, Performance, Burkina Faso

\section{Background}

In developing countries, a large number of chronic diseases such as diabetes remain undiagnosed [1] [2] [3]. Health systems limited in personnel, medical equipment and infrastructure are particularly focused on emergency and infectious disease management [4] [5] [6]. Yet the World Health Organization (WHO) estimates that by 2030, the most significant increase in the prevalence of chronic diseases such as diabetes will occur in developing countries [6] [7].

According to data from the International Diabetes Federation (IDF), the prevalence of diabetes mellitus for the African region was 19 million in 2019 [1]. Estimates for the same region reported a proportion of $60 \%$ of glyco-ignorant diabetics [1].

Burkina Faso, like other developing countries, is faced with the problem of the emergence of non-communicable diseases with its consequences in terms of morbidity and mortality, constituting a public health challenge. According to the STEPS survey on risk factors for non-communicable diseases, conducted in 2013 in the country: the prevalence of diabetes mellitus was $4.9 \%$ nationally [8]. However, screening for type 2 diabetes mellitus (T2DM) is not systematic in clinical practice. Blood glucose measurement had never been performed in $94.2 \%$ of the participants in the STEPS 2013 survey. Many patients are diagnosed with the cardinal signs of diabetes or with a complication [8].

In this context, it is important to implement a screening tool that is simple to use and non-invasive, at the practitioner's initiative, and that is used to recognize and early diagnose those at high risk of developing T2DM, and to make them a target for prevention and management strategies [9] [10]. The Finnish Diabetes Risk Score questionnaire (FINDRISC) is a validated, recommended and widely used risk assessment tool for the development of type 2 diabetes [11]. It estimates an individual's probability of developing type 2 diabetes within 10 years. The FINDRISC for T2DM provides a low-cost, accessible, non-invasive alternative for identifying risk groups. The use of this score should enable the implementation of primary prevention measures for diabetes [12] [13] [14]. 
However, the FINDRISC questionnaire was developed from a Finnish population and has been widely used in European studies [15]-[22]. Its performance in an African [23] [24] [25] [26] [27] population such as Burkina Faso, with different habits and lifestyles, has not been evaluated.

The objective of this study was to determine the prevalence of undiagnosed T2DM and to evaluate the diagnostic performance of the FINDRISC questionnaire for identifying type 2 diabetics in the urban population of Ouagadougou, Burkina Faso.

\section{Methodology}

\section{Framework of the study}

The study took place in the city of Ouagadougou, the political capital of Burkina Faso. Ouagadougou is a large urban center in epidemiological transition marked by a high burden of morbidity due to endemic epidemics and by the progressive increase in the burden of non-communicable diseases [8].

\section{Type and population of study}

We conducted a cross-sectional study. The target population of the study was the adult population of the city of Ouagadougou. This screening campaign was conducted in conjunction with World Diabetes Day 2019, which was dedicated to the theme "Family and Diabetes". In this context, a series of activities was initiated from November 11 to 16, 2019, including a diabetes screening campaign at five (5) sites spread throughout the city of Ouagadougou. These screening days were preceded by ten (10) days of information campaign through the media: television, radio and web. The information was given in French, then translated into the two (2) most widely spoken national languages including Mooré and Dioula.

All screening participants who were at least 18 years old and gave their oral consent were included in the study. We did not include known diabetic individuals and pregnant women in the analysis. Respondents whose blood glucose results were missing and those who had missing information for variables needed to calculate the FINDRISC score were excluded from the study.

\section{Data collection}

The collection tool was an anonymous questionnaire that included the variables of interest from the FINDRISC score and variables on participants' habits and lifestyles. The SD CodeFree ${ }^{\mathrm{TM}}$ Glucose Analyzer (SD BIOSENSOR, Inc.) was used to measure capillary blood glucose. The investigative team consisted of nurses and physicians trained in the technique of anthropometric measurements, capillary blood glucose measurement, blood pressure measurement and questionnaire administration. The questionnaire was translated orally into Mooré or Dioula for those who did not understand French.

To establish the diagnosis of diabetes mellitus, capillary whole blood was taken by finger prick and immediately analyzed using an SD CodeFree ${ }^{\mathrm{TM}}$ glucose analyzer. A control solution test was performed each time a new vial of strips 
was opened. All other procedures described by the manufacturer were followed. Blood pressure was measured, using a mercury sphyngomanometer, in a seated position, using the right arm after a five (5) minutes rest period. Only one measurement was taken during the interview. Height was measured in the standing position to the nearest centimetre $(\mathrm{cm})$ with a tape measure. Weight was measured with subjects in light clothing and without shoes, using a digital floor scale to the nearest $0.1 \mathrm{~kg}$. The body mass index (BMI) was calculated by dividing the weight $(\mathrm{kg})$ by the square of the height $\left(\mathrm{m}^{2}\right)$. In the standing position, waist circumference was measured using a tape measure placed midway between the lower part of the ribs (at the bottom of the last rib) and the iliac crest (the upper part of the pelvic bone). The value was measured to the nearest centimetre $(\mathrm{cm})$ at the end of a normal exhalation at navel height.

\section{Variables of interest in FINDRISC}

The variables of interest in FINDRISC were gender, which was categorized as either female or male. Age was a continuous variable that was reported as an age group. Family history of diabetes was categorized into three classes: no family history, immediate family history and other relatives. Weight was a numeric variable with a value expressed in kilograms $(\mathrm{kg})$. Normal weight, overweight and obesity were defined for BMIs between $18 \mathrm{~kg} / \mathrm{m}^{2}$ and $24.9 \mathrm{~kg} / \mathrm{m}^{2}$, between 25 $\mathrm{kg} / \mathrm{m}^{2}$ and $29.9 \mathrm{~kg} / \mathrm{m}^{2}$, and greater than or equal to $30 \mathrm{~kg} / \mathrm{m}^{2}$, respectively. Height was a numerical variable with a value expressed in centimetres $(\mathrm{cm})$. Body mass index (BMI) was a continuous variable expressed in $\mathrm{kg} / \mathrm{m}^{2}$. Waist circumference, which was a continuous variable expressed in centimetres $(\mathrm{cm})$. According to the thresholds, abdominal obesity was defined by a waist circumference greater than $80 \mathrm{~cm}$ for women and greater than $94 \mathrm{~cm}$ for men [28]. Daily physical activity of at least 30 minutes duration was dichotomized (yes or no). Daily fruit and vegetable consumption was dichotomized as either daily or not daily. For vegetables, respondents were asked how often they ate the equivalent of one bowl of fresh, raw, leafy green vegetables (spinach, lettuce, etc.) and half a bowl of other vegetables each day, cooked or raw, cut into small pieces (tomatoes, squash, green beans, etc.), or half a bowl of vegetable juice. For fruit, respondents were asked how often they consumed the daily consumption of the equivalent of one medium-sized fruit (orange, banana, apple, etc.) or half a bowl of fruit pieces, cooked (without artificial flavors). The history of hyperglycemia has been dichotomized (yes or no). Use of antihypertensive treatment was dichotomized (yes or no).

\section{Diabetes-related variables}

Diabetes was the dependent variable in our study. Capillary blood glucose was a continuous variable reported in $\mathrm{mmol} / \mathrm{l}$. Diabetes was defined by fasting capillary blood glucose (after at least 8 hours of fasting) $\geq 6.1 \mathrm{mmol} / \mathrm{L}$ or postprandial blood glucose $\geq 11.1 \mathrm{mmol} / \mathrm{L}$ [6].

The variables of interest in the Findrisc score were weighted with points ranging from 0 to 5 . The addition of the points of these eight (08) variables leads 
to a score ranging from 0 to 26 points [11]. A score below 7 points indicates an estimated low risk of $1 \%(1 / 100)$ of developing diabetes mellitus. A score of 7 11 points reflects a slightly elevated risk estimated at $4 \%(1 / 25)$ that will develop diabetes mellitus. A score of 12 - 14 points reflects an estimated moderate risk of $17 \%(1 / 6)$ that will develop diabetes mellitus. A score of $15-20$ points reflects an estimated high risk of $33 \%$ (1/3) that will develop diabetes mellitus. A score of more than 20 points indicates a very high risk estimated at 50\% (1/2) that will develop diabetes mellitus. A risk of $4 \%$ means that 4 out of 100 people with this score may develop type 2 diabetes within the next 10 years.

\section{Analysis}

The study population was described by numbers and frequencies for the qualitative variables. Quantitative variables were described by their mean and standard deviation. We estimated the prevalence of T2DM and its $95 \%$ confidence interval.

Receiver operating characteristic (ROC) curve analysis was used to study the diagnostic performance of FINDRISC for the identification of type 2 diabetics. The area under the ROC curve (AUC) was determined for the FINDRISC score. We also calculated the sensitivity (Se), specificity (Sp). The optimal threshold was determined by the sum of the highest sensitivity and specificity.

Multivariate logistic regression was used to analyze the association of each variable used in the calculation of the FINDRISC score. The final model was obtained using a manual stepwise top-down procedure. Thus, the variables with the highest $\mathrm{p}$-values $>0.05$ were removed one by one as the procedure progressed.

\section{Ethical consideration}

The oral consent of screening participants was a prerequisite for the administration of the questionnaire. The questionnaire was anonymous.

\section{Results}

A total of 1276 individuals were included in the analyses, of which 667 (52.27\%) were women. The average age was 34.16 years (standard deviation [SD]: \pm 12.42 ), with extremes ranging from 18 to 80 years. Approximately 1006 (78.84\%) of the participants were under 45 years of age. A total of $40.28 \%$ of participants presented with abdominal obesity, $26.49 \%$ with overweight and $14.81 \%$ with obesity (Table 1).

The prevalence of diabetes was $10.74 \%$. The mean FINDRISC score was 5.85 points (SD: \pm 4.31 points) with extremes ranging from 0 to 23 . The majority $(58.54 \%)$ of individuals had a low risk of diabetes according to the Findrisc score $0-7$, while $3.61 \%$ had a score $\geq 15$ (Table 1 ).

A significant association was found between the FINDRISC score and the probability of being diagnosed with diabetes with OR $=1.17$ ( $\mathrm{p}<0.001,95 \%$ CI $=1.13 ; 1.22$ ). The AUC of predictive ability of the FINDRISC score in our study population was 0.70 (95\% CI: 0.65 - 0.74) (Figure 1). 
Table 1. Description of inclusion participants $(\mathrm{N}=1276)$.

\begin{tabular}{ccc}
\hline & Total (n) & Percentage (\%) \\
\hline Gender & & \\
\hline Female & 667 & 52.27 \\
Male & 609 & 47.13 \\
\hline Age & & \\
\hline$<35$ years & 747 & 58.54 \\
{$[35$ - 45 years[ } & 259 & 20.30 \\
{$[45$ - 55 years[ } & 164 & 12.85 \\
{$[55$ - 64 years $]$} & 77 & 6.03 \\
$>64$ years & 29 & 2.27 \\
\hline Family History of Diabetes & 1027 & 80.49 \\
\hline No & 132 & 10.34 \\
\hline Immediate family & 117 & 9.17 \\
\hline Other relatives & &
\end{tabular}

Daily physical activity $\geq 30$ minutes

\begin{tabular}{|c|c|c|}
\hline Yes & 631 & 49.45 \\
\hline No & 645 & 50.55 \\
\hline \multicolumn{3}{|c|}{ Daily consumption vegetables, fruits, berries } \\
\hline No & 1077 & 84.40 \\
\hline Yes & 199 & 15.60 \\
\hline \multicolumn{3}{|c|}{ History of antihypertensive medication } \\
\hline Yes & 94 & 7.37 \\
\hline No & 1182 & 92.63 \\
\hline \multicolumn{3}{|c|}{ History of impaired blood glucose } \\
\hline Yes & 60 & 4.70 \\
\hline No & 1216 & 95.30 \\
\hline \multicolumn{3}{|l|}{ Waist circumference ${ }^{c}$} \\
\hline $\mathrm{F}<80 \mathrm{~cm} ; \mathrm{M}<94 \mathrm{~cm}$ & 762 & 59.72 \\
\hline $\begin{array}{l}\mathrm{F}: \geq 80 \text { and }<88 \mathrm{~cm} \\
\mathrm{M}: \geq 94 \text { et }<102 \mathrm{~cm}\end{array}$ & 230 & 18.03 \\
\hline $\mathrm{F}: \geq 88 \mathrm{~cm} ; \mathrm{M}: \geq 102 \mathrm{~cm}$ & 284 & 22.26 \\
\hline \multicolumn{3}{|l|}{ Body mass index $\left[\mathrm{kg} / \mathrm{m}^{2}\right]$} \\
\hline$<25^{\mathrm{d}}$ & 749 & 58.70 \\
\hline$[25-30]^{e}$ & 338 & 26.49 \\
\hline$>30^{\mathrm{f}}$ & 189 & 14.81 \\
\hline \multicolumn{3}{|l|}{ Diabetes type 2} \\
\hline No & 1139 & 89.26 \\
\hline Yes & 135 & 10.74 \\
\hline
\end{tabular}




\section{Continued}

\begin{tabular}{ccc}
\hline Findrisc Score (points) & & \\
\hline Score $0-7$ & 747 & 58.54 \\
Score $7-11$ & 386 & 30.25 \\
Score $12-14$ & 97 & 7.60 \\
Score $15-20$ & 43 & 3.37 \\
Score more than 20 & 3 & 0.24 \\
\hline
\end{tabular}

Abbreviations: M: male; F: female; cm: centimeter; kg: kilogram; m: meter; a: Immediate family: close relatives, i.e., father, mother, children, sisters, brothers; b: Other relatives: distant relatives, i.e., grandparents, aunts, uncles, cousins; c: Thresholds of waist circumference were defined by the reference 28. d: Normal: BMI $<25 \mathrm{~kg} / \mathrm{m}^{2}$; e: Overweight: BMI [25 - $30 \mathrm{~kg} / \mathrm{m}^{2}\left[\right.$; : Obesity: BMI $\geq 30 \mathrm{~kg} / \mathrm{m}^{2}$.

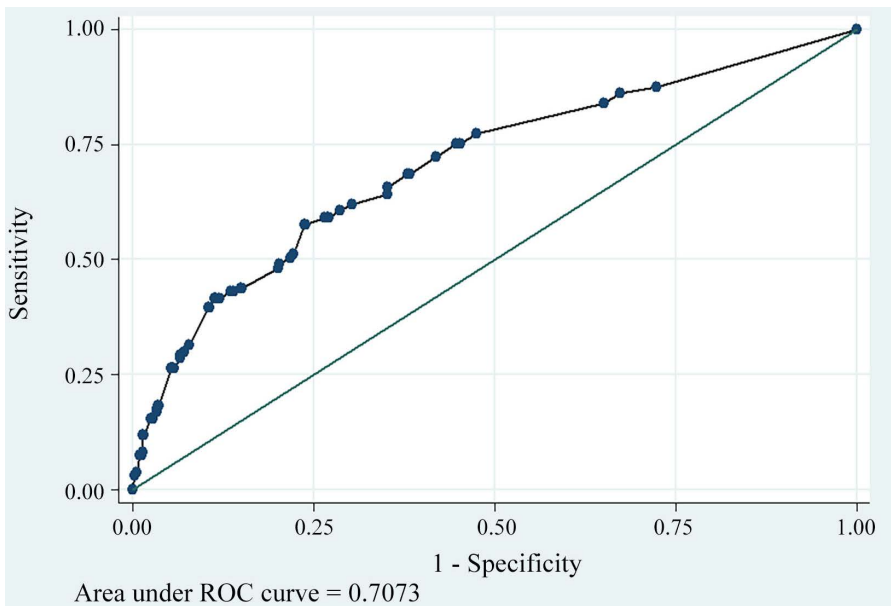

Figure 1. ROC curve of diabetes and FINDRISC.

Table 2 presents the sensitivity and specificity associated with each threshold of the FINDRISC score. The optimal cut-off score value $\geq 7$ was the best predictor of the likelihood of having T2DM.

In multivariate analysis, age $(\mathrm{p}<0.001)$, daily physical activity $(\mathrm{p}=0.004)$, use of antihypertensive medication $(p=0.007)$ and waist circumference $(p<0.001)$ were significantly associated with the risk of developing diabetes (Table 3 ).

\section{Discussion}

In this study including adult volunteers from the city of Ouagadougou, the prevalence of undiagnosed type 2 diabetes was high (10.74\%). The FINDRISC score showed good performance (AUC $=0.70)$ in identifying undiagnosed type $2 \mathrm{di}$ abetics. However, the variables in the score that best predicted the likelihood of being diabetic were age, daily physical activity, use of antihypertensive medication and waist circumference.

\section{Prevalence of diabetes mellitus}

The prevalence of diabetes was $10.74 \%$ in our study. The prevalence of diabetes in our study was higher than that of the national baseline survey on noncommunicable diseases in Burkina Faso for the central region (4.9\%) [8]. Millo- 
go also reported a low prevalence of 5.8\% in a Burkinabe national cohort [29]. Our diabetes prevalence remained high compared to that reported by the International Diabetes Federation (IDF) of Burkina Faso (7\% - 8\%) [1].

It is currently accepted that interventions on diet and/or exercise can significantly reduce the incidence of T2DM, even for people with glucose intolerance [30] [31] [32]. However, abdominal obesity, overweight and obesity were found in proportions of $40.28 \%, 26.49 \%$ and $14.81 \%$ respectively in our study. These proportions, excluding abdominal obesity, were similar to those found in the STEPS wise for the central region, with proportions of $48.7 \%, 30.6 \%$ and $16.1 \%$ respectively for abdominal obesity, overweight and obesity [8].

\section{FINDRISC scores}

The study identified a score $<7$ (no or little risk in the next 10 years) in the majority (58.54\%) of participants, between 7 and 11 (cautious, slightly increased risk) of 30.25\%, between 12 and 14 (start implementing prevention measures) of $7.60 \%$, between 15 and 20 (really at risk, danger) of 3.37\%, and $>20$ (the need for action is imminent) in $0.24 \%$.

Table 2. Threshold value predictive of diabetes risk in the coming years.

\begin{tabular}{|c|c|c|c|c|}
\hline Threshold & Sensitivity (Se) & Specificity (Sp) & $\mathrm{Se}+\mathrm{Sp}$ & Classification \\
\hline$\geq 0$ & $100.00 \%$ & $0.00 \%$ & $100.00 \%$ & $10.74 \%$ \\
\hline$\geq 1$ & $100.00 \%$ & $5.44 \%$ & $105.44 \%$ & $15.60 \%$ \\
\hline$\geq 2$ & $91.24 \%$ & $22.74 \%$ & $113.98 \%$ & $30.09 \%$ \\
\hline$\geq 3$ & $90.51 \%$ & $28.01 \%$ & $118.52 \%$ & $34.72 \%$ \\
\hline$\geq 4$ & $86.13 \%$ & $41.88 \%$ & $128.01 \%$ & $46.63 \%$ \\
\hline$\geq 5$ & $76.64 \%$ & $48.90 \%$ & $125.54 \%$ & $51.88 \%$ \\
\hline$\geq 6$ & $74.45 \%$ & $52.85 \%$ & $127.30 \%$ & $55.17 \%$ \\
\hline$\geq 7$ & $70.80 \%$ & $62.07 \%$ & $132.87 \%$ & $63.01 \%$ \\
\hline$\geq 8$ & $61.31 \%$ & $69.36 \%$ & $130.67 \%$ & $68.50 \%$ \\
\hline$\geq 9$ & $48.91 \%$ & $76.03 \%$ & $124.94 \%$ & $73.12 \%$ \\
\hline$\geq 10$ & $42.34 \%$ & $81.30 \%$ & $123.64 \%$ & $77.12 \%$ \\
\hline$\geq 11$ & $37.23 \%$ & $86.48 \%$ & $123.71 \%$ & $81.19 \%$ \\
\hline$\geq 12$ & $28.47 \%$ & $90.87 \%$ & $119.34 \%$ & $84.17 \%$ \\
\hline$\geq 13$ & $24.09 \%$ & $93.59 \%$ & $117.68 \%$ & $86.13 \%$ \\
\hline$\geq 14$ & $16.79 \%$ & $96.05 \%$ & $112.84 \%$ & $87.54 \%$ \\
\hline$\geq 15$ & $12.41 \%$ & $97.45 \%$ & $109.86 \%$ & $88.32 \%$ \\
\hline$\geq 16$ & $6.57 \%$ & $98.51 \%$ & $105.08 \%$ & $88.64 \%$ \\
\hline$\geq 17$ & $6.57 \%$ & $99.21 \%$ & $105.78 \%$ & $89.26 \%$ \\
\hline$\geq 18$ & $2.19 \%$ & $99.65 \%$ & $101.84 \%$ & $89.18 \%$ \\
\hline$\geq 19$ & $1.46 \%$ & $99.82 \%$ & $101.28 \%$ & $89.26 \%$ \\
\hline$\geq 21$ & $1.46 \%$ & $99.91 \%$ & $101.37 \%$ & $89.34 \%$ \\
\hline$\geq 23$ & $0.73 \%$ & $100.00 \%$ & $100.73 \%$ & $89.34 \%$ \\
\hline$>23$ & $0.00 \%$ & $100.00 \%$ & $1000.0 \%$ & $89.26 \%$ \\
\hline
\end{tabular}


Table 3. Univariate and multivariate analyses.

\begin{tabular}{|c|c|c|c|c|c|c|c|}
\hline & \multirow{2}{*}{$\begin{array}{l}\text { n diabetic/ } \\
\mathrm{N} \text { total }\end{array}$} & \multicolumn{3}{|c|}{ Univariate } & \multicolumn{3}{|c|}{ Multivariate } \\
\hline & & OR & $95 \%$ IC & $\mathrm{p}$ & OR & $95 \%$ IC & $\mathrm{p}$ \\
\hline \multicolumn{8}{|l|}{ Gender } \\
\hline Female & $86 / 667$ & 1 & & & & & \\
\hline Male & $51 / 609$ & 0.61 & $0.42 ; 0.88$ & 0.010 & & & \\
\hline Age & & & & & & & $<0.001$ \\
\hline$<35$ years & $43 / 747$ & 1 & & $<0.001$ & 1 & & \\
\hline$[35-45$ years [ & $41 / 259$ & 3.07 & $1.95 ; 4.84$ & $<0.001$ & 2.42 & $1.51 ; 3.89$ & $<0.001$ \\
\hline$[45-55$ years [ & $30 / 164$ & 3.65 & $2.21 ; 6.05$ & $<0.001$ & 2.33 & $1.36 ; 4.01$ & 0.002 \\
\hline [55 - 64 years $]$ & $17 / 77$ & 4.63 & $2.49 ; 8.62$ & $<0.001$ & 2.81 & $1.46 ; 5.41$ & 0.002 \\
\hline$>64$ years & $6 / 29$ & 4.27 & $1.5 ; 11.04$ & $<0.001$ & 2.59 & $0.95 ; 7.05$ & 0.06 \\
\hline Family history of diabetes & & & & 0.20 & & & \\
\hline No & $102 / 1027$ & 1 & & & & & \\
\hline Immediate family $^{\mathrm{a}}$ & $22 / 132$ & 1.81 & $1.09 ; 2.99$ & 0.02 & & & \\
\hline Other relatives $^{\mathrm{b}}$ & $13 / 117$ & 1.13 & $0.61 ; 2.08$ & 0.68 & & & \\
\hline \multicolumn{8}{|c|}{ Daily physical activity $\geq 30$ minutes } \\
\hline Yes & $46 / 645$ & 0.45 & $0.31 ; 0.66$ & $<0.001$ & 0.56 & $0.38 ; 0.82$ & 0.004 \\
\hline No & $91 / 631$ & 1 & & & 1 & & \\
\hline \multicolumn{8}{|c|}{ Daily consumption vegetables, fruits, berries } \\
\hline Yes & $122 / 1077$ & 1 & & & & & \\
\hline No & $15 / 199$ & 0.63 & $0.36 ; 1.11$ & 0.11 & & & \\
\hline \multicolumn{8}{|c|}{ History of antihypertensive medication } \\
\hline Yes & $25 / 94$ & 3.46 & $2.10 ; 5.69$ & $<0.001$ & 2.09 & $1.22 ; 3.60$ & 0.007 \\
\hline No & $112 / 1182$ & & 1 & & 1 & & \\
\hline \multicolumn{8}{|l|}{ History of impaired blood glucose } \\
\hline Yes & $14 / 60$ & 2.70 & $1.45 ; 5.06$ & 0.002 & & & \\
\hline No & $123 / 1216$ & & & & & & \\
\hline Waist circumference $^{c}$ & & & & $<0.001$ & & & $<0.001$ \\
\hline $\begin{array}{l}\mathrm{F}<80 \mathrm{~cm} \\
\mathrm{M}<94 \mathrm{~cm}\end{array}$ & $48 / 762$ & 1 & & & 1 & & \\
\hline $\begin{array}{c}\mathrm{F}: \geq 80 \text { and }<88 \mathrm{~cm} \\
\mathrm{M}: \geq 94 \text { and }<102 \mathrm{~cm}\end{array}$ & $31 / 230$ & 2.31 & $1.43 ; 3.73$ & 0.001 & 1.59 & $0.97 ; 2.63$ & 0.06 \\
\hline $\begin{array}{c}\mathrm{F}: \geq 88 \mathrm{~cm} \\
\mathrm{M}: \geq 102 \mathrm{~cm}\end{array}$ & $58 / 284$ & 3.81 & $2.53 ; 5.75$ & $<0.001$ & 2,39 & $1.53 ; 3.71$ & $<0.001$ \\
\hline Body mass index $\left[\mathrm{kg} / \mathrm{m}^{2}\right]$ & & & & $<0.001$ & & & \\
\hline$<25^{\mathrm{d}}$ & $50 / 749$ & 1 & & & & & \\
\hline$[25-30]^{e}$ & $54 / 338$ & 2.65 & $1.76 ; 3.99$ & $<0.001$ & & & \\
\hline$>30^{\mathrm{f}}$ & $33 / 189$ & 2.95 & $1.83 ; 4.74$ & $<0.001$ & & & \\
\hline
\end{tabular}

Abbreviations: OR: odds ratio; CI: confidence interval; p: value; M: male; F: female; cm: centimeter; kg: kilogram; m: meter; a: Immediate family: close relatives, i.e., father, mother, children, sisters, brothers; b: Other relatives: distant relatives, i.e., grandparents, aunts, uncles, cousins; c: Thresholds of waist circumference were defined by the reference 28; d: Normal: BMI $<25 \mathrm{~kg} / \mathrm{m}^{2}$; e: Overweight: BMI [25 - $30 \mathrm{~kg} / \mathrm{m}^{2}$ [; f: Obesity: BMI $\geq 30 \mathrm{~kg} / \mathrm{m}^{2}$. 
In Burkina Faso, Bagbila in a student study [33], found that $95.7 \%$ of participants had a score of less than 7 . We included individuals between 18 and 80 years of age in the study, so our proportion could be explained by the advanced age of the participants in our study. Older volunteers may have multiple risk factors for diabetes compared to younger students. Indeed, the American Diabetes Association 2015 recommended screening for diabetes for all subjects aged 45 years and older and also for subjects with multiple risk factors for diabetes [34].

In Africa, compared to our score of less than 7 (58.54\%), Omech in Botswana [24], Olamoyegun in Nigeria [25] and Azzouz in Algeria [27] had lower scores of $15.1 \%, 14 \%$ and $7.9 \%$ respectively. While Metonnou-Adanhoume in Benin [26] reported a high score of $68.28 \%$. These differences in the proportion of scores are methodological: small sample size for the Botswana study [24]; semi-urban setting for the Nigerian study versus urban [25]; retrospective collection with data from 2006 for the Benin study versus prospective [26]. As for the Algerian study, the difference would be due to the eating habits and lifestyles of its populations [27].

In Europe, Mavrogianni in a large cohort study (six European countries) [35], with participants in the same age group as our study, found a proportion of $16.4 \%$. Our score frequency of less than 7 was not surprising as only $4.7 \%$ of our study population reported a history of hyperglycemia. This low rate could be explained by the lack of data regarding the history of hyperglycemia in our study volunteers in a context of low socio-economic level marked by the absence of health insurance and $94.2 \%$ of the Burkinabe population had never performed blood glucose testing [8]. The history of hyperglycemia was not only a determining factor in the calculation of the final FINDRISC score because it alone accounted for 5 points, but also in the original FINDRISC study, it was the variable that had the greatest predictive power for T2DM [11].

\section{Threshold value of the score}

In our study, we found a threshold score value $\geq 7$ that predicted well the risk of T2DM diagnosis because the area under the ROC curve was 0.73 with a sensitivity of $70.8 \%$ and a specificity of $62.07 \%$.

Compared to the African studies, our prediction score threshold value was close to that of the Beninese study ( $\geq 8.5)$ in West Africa [26] and lower than that of the Algerian studies ( $\geq 13$ for women and $\geq 11$ for men) in North Africa [27] and Botswana $(\geq 17)$ in Southern Africa [2].

As for the European series, the Evaluation of Screening and Early Detection Strategies for Type 2 Diabetes and Impaired Glucose Tolerance study (DETECT2) [22] reported a prediction score threshold value identical to that of our study. Our prediction score threshold value was similar to that reported in both the original FINDRISC study and the European cross-sectional studies in which the threshold values varied widely from 9 to 15 [11] [18] [36].

FINDRISC performance

According to a systematic review, diabetes prediction scores in general do not 
appear to be applicable to African populations. Indeed, the authors of this systematic review reported that family history of diabetes and personal history of hypertension were the main variables causing bias and therefore source of error in the African context of information [23]. However, the International Diabetes Federation (IDF) and European guidelines recommend targeted screening for diabetes, and favour risk scores and questionnaires to identify subjects at high risk of T2DM, and who should benefit from biological screening [12]. These scores offer an accessible, non-invasive means of diabetes prevention in a health care setting where biological means are not available, and do not require any additional financial means for the patient [12] [13] [14]. As such, the Finnish risk score developed in the Finnish population [11], is considered as a tool that is easy to apply in clinical practice, validated and discriminating in the Caucasian population [15]-[22].

The discriminating qualities of scores from studies in different African countries are varied. In West Africa (Benin), one study gave an AUC of 0.86 [26]. In North Africa (Algeria) an AUC of 0.67 was scored [27]. And in Southern Africa Botswana, an AUC of 0.63 was found [24]. Compared to our results, the Beninese study [26] is the only African study that predicted very well (AUC $=0.86$ ) the risk of developing diabetes. Moreover, the results of the Botswana study (0.63) and those of the Algerian study (0.67) were not sufficiently discriminating in the prediction of the risk of diabetes than those of our study.

In the DETECT-2 study which involved European, Australian and African populations (Mauritania), the authors found an AUC of 0.76 with a sensitivity of $76 \%$ and a specificity of $63 \%$ [22]. This study highlighted the good performance of FINDRISC in european population only [22]. The difference in performance of the FINDRISC score between different populations can be explained by the diabetes risk factors specific to each locality (eating habits, lifestyle, genetics, etc.) which may have a different impact in different populations [22]. Nevertheless, these results were close to those of our study in both prediction and specificity indicating early and optimal management. The same trend of lower specificity was found in the original FINDRISC study with a sensitivity of $81 \%$ and a specificity of $76 \%$. However, very good predictive power was reported in the original FINDRISC study with an area under the ROC curve of 0.85 [11]. The area under the ROC curve was also reported to be 0.85 [11]. As for the different scores developed in non-African contexts, the area under the ROC curve ranged from 0.63 to 0.8 in studies evaluating their performance in the populations concerned [23].

\section{Factors associated with the FINDRISC score}

In our study, in multivariate analysis, age $(\mathrm{p}<0.001)$, daily physical activity ( $\mathrm{p}$ $=0.004)$, use of antihypertensive medication $(\mathrm{p}=0.007)$ and waist circumference $(\mathrm{p}<0.001)$ were score variables significantly associated with the risk of T2DM developing.

In the European cohort led by Mavrogianni, in multivariate analysis, age 
greater than 45 years, body mass index greater than $30 \mathrm{~kg} / \mathrm{m}^{2}$, and history of hyperglycemia were statistically associated variables [35].

It seems that some of the variables that make up the original findrisc score can be removed depending on the specificities of populations around the world. While it is true that diabetes risk assessment should be validated for each population under consideration it seems appropriate to make changes to the Findrisc questionnaire if it is applied to other ethnic groups [27] [37].

\section{Limitations of the study}

This study assessed the performance of FINDRISC in an African population in the south of the Sahara. However, there were limitations and biases that need to be taken into account when interpreting the results. These were related to:

- an overestimation bias due to the lack of repeat blood sampling to retain the diagnosis of diabetes mellitus as suggested by the recommendations of learned societies.

- a selection bias due to the awareness campaign conducted in the media in the days preceding the screening. This could explain the high prevalence of T2DM found in our study. However, this sample is not representative of the entire population making it difficult to generalize the data from this study.

\section{Conclusion}

The Finnish Diabetes Risk Score (FINDRISC) predicts well the risk of occurrence of dysglycemia in Burkina Faso. It is a score that should be promoted in daily clinical practice because it is easy to use, inexpensive and does not require blood sampling in a context of insufficient medical-technical equipment (countries with limited resources) and in the absence of universal health insurance. This will allow early screening and management of T2DM by identifying those at risk who will benefit from blood sampling for confirmation at a later stage.

A future study will be indicated to see if the Findrisc score variables can be modified according to local peculiarities, based on the results of this study.

\section{Conflicts of Interest}

The authors declare no conflicts of interest regarding the publication of this paper.

\section{References}

[1] International Diabetes Federation (2019) Diabetes Atlas 9th Edition. IDF, Brussels. https://www.diabetesatlas.org/en

[2] Asmelash, D. and Asmelash, Y. (2019) The Burden of Undiagnosed Diabetes Mellitus in Adult African Population: A Systematic Review and Meta-Analysis. Journal of Diabetes Research, 2019, Article ID: 4134937. https://doi.org/10.1155/2019/4134937

[3] Animaw, W. and Seyoum, Y. (2017) Increasing Prevalence of Diabetes Mellitus in a Developing Country and Its Related Factors. PLOS ONE, 12, e0187670. https://doi.org/10.1371/journal.pone.0187670 
[4] Mathers, C.D. and Loncar, D. (2006) Projections of Global Mortality and Burden of Disease from 2002 to 2030. PLoS Medicine, 3, e442. https://doi.org/10.1371/journal.pmed.0030442

[5] Diop, S.N., Djrolo, F., Traoré Sidibé, A., Baldé, N.M., Monabeka, H.G. and Epaka, M.E. (2019) Consensus pour la prise en charge de l'hyperglycémie dans le diabète de type 2 en Afrique subsaharienne. Rédigé par un groupe d'experts africains du diabète. Médecine des Maladies Métaboliques, 13, 210-216. https://doi.org/10.1016/S1957-2557(19)30057-4

[6] Roglic, G. and World Health Organization (2016) Global Report on Diabetes. World Health Organization, Geneva, 86.

[7] Gakidou, E., Mallinger, L., Abbott-Klafter, J., Guerrero, R., Villalpando, S. and Ridaura, R.L. (2011) Management of Diabetes and Associated Cardiovascular Risk Factors in Seven Countries: A Comparison of Data from National Health Examination Surveys. Bulletin of the World Health Organization, 89, 172-183. https://doi.org/10.2471/BLT.10.080820

[8] Organisation mondiale de la Santé (OMS) (2014) Burkina Faso_2013_STEPS_Report. OMS, 10-363-A-10, 81.

[9] Paulweber, B., Valensi, P., Lindström, J., Lalic, N.M., Greaves, C.J. and McKee, M. (2010) A European Evidence-Based Guideline for the Prevention of Type $2 \mathrm{Di}$ abetes. Hormone and Metabolic Research, 42, 3-36. https://doi.org/10.1055/s-0029-1240928

[10] Alberti, K.G., Zimmet, P. and Shaw, J. (2007) International Diabetes Federation: A Consensus on Type 2 Diabetes Prevention. Diabetic Medicine, 24, 451-463. https://doi.org/10.1111/j.1464-5491.2007.02157.x

[11] Lindström, J. and Tuomilehto, J. (2003) The Diabetes Risk Score: A Practical Tool to Predict Type 2 Diabetes Risk. Diabetes Care, 26, 725-731. https://doi.org/10.2337/diacare.26.3.725

[12] International Diabetes Federation (2018) Recommendations for Managing Type 2 Diabetes in Primary Care-2017. Classification and Diagnosis of Diabetes. Standards of Medical Care in Diabetes-2018. Diabetes Care, 41, 13-27.

[13] Ryden, L., Grant, P.J., Anker, S.D., Berne, C. and Cosentino, F. (2013) ESC Guidelines on Diabetes, Pre-Diabetes, and Cardiovascular Diseases Developed in Collaboration with the EASD: The Task Force on Diabetes, Pre-Diabetes, and Cardiovascular Diseases of the European Society of Cardiology (ESC) and Developed in Collaboration with the European Association for the Study of Diabetes (EASD). European Heart Journal, 34, 3035-3087.

https://doi.org/10.1093/eurheartj/eht108

[14] Khunti, K., Gillies, C.L., Taub, N.A., Mostafa, S.A., Hiles, S.L. and Abrams, K.R. (2012) A Comparison of Cost per Case Detected of Screening Strategies for Type 2 Diabetes and Impaired Glucose Regulation: Modelling Study. Diabetes Research and Clinical Practice, 97, 505-513. https://doi.org/10.1016/j.diabres.2012.03.009

[15] Costa, B., Barrio, F., Pinol, J.L., Cabre, J.J., Mundet, X. and Sagarra, R. (2013) Shifting from Glucose Diagnosis to the New HbA1c Diagnosis Reduces the Capability of the Finnish Diabetes Risk Score (FINDRISC) to Screen for Glucose Abnormalities within a Real-Life Primary Healthcare Preventive Strategy. BMC Medicine, 11, 45. https://doi.org/10.1186/1741-7015-11-45

[16] Franciosi, M., De Berardis, G., Rossi, M.C., Sacco, M., Belfiglio, M. and Pellegrini, F. (2005) Use of the Diabetes Risk Score for Opportunistic Screening of Undiagnosed Diabetes and Impaired Glucose Tolerance: The IGLOO (Impaired Glucose Toler- 
ance and Long-Term Outcomes Observational) Study. Diabetes Care, 28, 11871194. https://doi.org/10.2337/diacare.28.5.1187

[17] Li, J., Bergmann, A., Reimann, M., Bornstein, S.R. and Schwarz, P.E. (2009) A More Simplified Finnish Diabetes Risk Score for Opportunistic Screening of Undiagnosed Type 2 Diabetes in a German Population with a Family History of the Metabolic Syndrome. Hormone and Metabolic Research, 41, 98-103. https://doi.org/10.1055/s-0028-1087191

[18] Makrilakis, K., Liatis, S., Grammatikou, S., Perrea, D., Stathi, C. and Tsiligros, P. (2011) Validation of the Finnish Diabetes Risk Score (FINDRISC) Questionnaire for Screening for Undiagnosed Type 2 Diabetes, Dysglycaemia and the Metabolic Syndrome in Greece. Diabetes \& Metabolism, 37, 144-151.

https://doi.org/10.1016/j.diabet.2010.09.006

[19] Saaristo, T., Peltonen, M., Lindstrom, J., Saarikoski, L., Sundvall, J. and Eriksson, J.G. (2005) Cross-Sectional Evaluation of the Finnish Diabetes Risk Score: A Tool to Identify Undetected Type 2 Diabetes, Abnormal Glucose Tolerance and Metabolic Syndrome. Diabetes and Vascular Disease Research, 2, 67-72. https://doi.org/10.3132/dvdr.2005.011

[20] Salinero-Fort, M.A., Burgos-Lunar, C., Lahoz, C., Mostaza, J.M., Abanades-Herranz, J.C. and Laguna-Cuesta, F. (2016) Performance of the Finnish Diabetes Risk Score and a Simplified Finnish Diabetes Risk Score in a Community-Based, CrossSectional Programme for Screening of Undiagnosed Type 2 Diabetes Mellitus and Dysglycaemia in Madrid, Spain: The SPREDIA-2 Study. PLOS ONE, 11, e0158489. https://doi.org/10.1371/journal.pone.0158489

[21] Tankova, T., Chakarova, N., Atanassova, I. and Dakovska, L. (2011) Evaluation of the Finnish Diabetes Risk Score as a Screening Tool for Impaired Fasting Glucose, Impaired Glucose Tolerance and Undetected Diabetes. Diabetes Research and Clinical Practice, 92, 46-52. https://doi.org/10.1016/j.diabres.2010.12.020

[22] Alssema, M., Vistisen, D., Heymans, M.W. and DETECT-2 Collaboration (2011) The Evaluation of Screening and Early Detection Strategies for Type 2 Diabetes and Impaired Glucose Tolerance (DETECT-2) Update of the Finnish Diabetes Risk Score for Prediction of Incident Type 2 Diabetes. Diabetologia, 54, 1004-1012. https://doi.org/10.1007/s00125-010-1990-7

[23] Mbanya, V., Hussain, A. and Kengne, A.P. (2015) Application and Applicability of Non-Invasive Risk Models for Predicting Undiagnosed Prevalent Diabetes in Africa: A Systematic Literature Search. Primary Care Diabetes, 9, 317-329. https://doi.org/10.1016/j.pcd.2015.04.004

[24] Omech, B., Mwita, J.C., Tshikuka, J.-G., Tsima, B., Nkomazna, O. and Kennedy, A.-P. (2016) Validity of the Finnish Diabetes Risk Score for Detecting Undiagnosed Type 2 Diabetes among General Medical Outpatients in Botswana. Journal of Diabetes Research, 2016, Article ID: 4968350. https://doi.org/10.1155/2016/4968350

[25] Olamoyegun, A.M., Oluyombo, R. and Iwuala, O.S. (2017) The Performance of the Finnish Diabetes Risk Score (FINDRISC) Questionaire for Screening Individuals with Undiagnosed Type 2 Diabetes and Dysglycaemia in Nigeria. British Journal of Medicine \& Medical Research, 19, 1-8. https://doi.org/10.9734/BJMMR/2017/31022

[26] Metonnou-Adanhoume, C.G., Agueh, V., Azandjeme, C.S., Sossa, C.J., Kpozehouen, A., Hessou, J., Darboux, J. and Paraïso, M.N. (2019) Optimal Threshold of the Finnish Diabetes Risk Score (FINDRISC) for Screening At-Risk Adults in an African Population in Southern Benin. Universal Journal of Public Health, 7, 63-72. https://doi.org/10.13189/ujph.2019.070204

[27] Azzouz, M., Boudiba, A., Guerchani, M.K., Lyes, Y., Hannachi, R., Baghous, H., 
Meftah, A. and Mimouni, S. (2014) Apport du score de risque finlandais FINDRISC dans l'identification de la dysglycemie dans une population algeroise, Algerie. Médecine des maladies Métaboliques, 8, 532-538. https://doi.org/10.1016/S1957-2557(14)70877-6

[28] Alberti, K.G.M.M., Zimmet, P. and Shaw, J. (2005) The Metabolic Syndrome-A New Worldwide Definition. The Lancet, 366, 1059-1062. https://doi.org/10.1016/S0140-6736(05)67402-8

[29] Millogo, T., Bicaba, B.W., Soubeiga, J.K., Dabiré, E., Médah, I. and Kouanda, S. (2018) Diabetes and Abnormal Glucose Regulation in the Adult Population of Burkina Faso: Prevalence and Predictors. BMC Public Health, 18, 350. https://doi.org/10.1186/s12889-018-5257-4

[30] Kosaka, K., Noda, M. and Kuzuya, T. (2005) Prevention of Type 2 Diabetes by Lifestyle Intervention: A Japanese Trial in IGT Males. Diabetes Research and Clinical Practice, 67, 152-162. https://doi.org/10.1016/j.diabres.2004.06.010

[31] Lindström, J., Peltonen, M. and Eriksson, J.G. (2008) Determinants for the Effectiveness of Lifestyle Intervention in the Finnish Diabetes Prevention Study. Diabetes Care, 31, 857-862. https://doi.org/10.2337/dc07-2162

[32] Pan, X.R., Li, G.W. and Hu, Y.H. (1997) Effects of Diet and Exercise in Preventing NIDDM in People with Impaired Glucose Tolerance. The Da Qing IGT and Diabetes Study. Diabetes Care, 20, 537-544. https://doi.org/10.2337/diacare.20.4.537

[33] Bagbila, W.P., Naone, M., Yaméogo, T.M., Kyelem, C.G., Sagna, Y., Ilboudo, A., Ouédraogo, S.M. and Drabo, Y.J. (2019) Score clinique finlandais de risque de diabète de type 2 et facteurs de risque en milieu estudiantin au Burkina Faso. Médecine des maladies Métaboliques, 13, 459-463. https://doi.org/10.1016/S1957-2557(19)30126-9

[34] American Diabetes Association (2015) Classification and Diagnosis of Diabetes. Diabetes Care, 38, S8-S16. https://doi.org/10.2337/dc15-S005

[35] Mavrogianni, C., Lambrinou, C.-P., Androutsos, O., Lindström, J., Kivelä, J., Cardon, G., Huys, N., Tsochev, K., Iotova, V., Chakarova, N., Rurik, I., Moreno, L.A., Liatis, S., Makrilakis, K. and Manios, Y. (2019) Evaluation of the Finnish Diabetes Risk Score as a Screening Tool for Undiagnosed Type 2 Diabetes and Dysglycaemia among Early Middle-Aged Adults in a Large-Scale European Cohort. The Feel4Diabetes-Study. Diabetes Research and Clinical Practice, 150, 99-110.

https://doi.org/10.1016/j.diabres.2019.02.017

[36] Salinero-Fort, M.Á., De Burgos-Lunar, C., Mostaza Prieto, J., Lahoz Rallo, C., Abánades-Herranz, J.C., Gómez-Campelo, P., et al. (2015) Validating Prediction Scales of Type 2 Diabetes Mellitus in Spain: The SPREDIA-2 Population-Based Prospective Cohort Study Protocol. BMJ Open, 5, e007195.

https://doi.org/10.1136/bmjopen-2014-007195

[37] Schmid, R., Vollenweider, P. and Waeber, G. (2011) Estimating the Risk of Developing Type 2 Diabetes: A Comparison of Several Risk Scores. Diabetes Care, 34, 1863-1868. https://doi.org/10.2337/dc11-0206 
Appendix 1. Finnish Diabetes Risk Score (FINDRISC) questionnaire [11].

\begin{tabular}{c}
\hline Variables du score Findrisc \\
\hline Age \\
$<35$ years \\
{$[35-45$ years [} \\
{$[45-55$ years [} \\
{$[55-64$ years $]$} \\
$>64$ years
\end{tabular}

Score

Family history of diabetes

$\begin{array}{cc}\text { No } & 0 \\ \text { Immediate family } & 5 \\ \text { Other relatives } & 3\end{array}$

Daily physical activity $\geq 30$ minutes

Yes 0

No

Daily consumption vegetables, fruits, berries

Yes 0

No 1

History of antihypertensive medication

Yes 2

No $\quad 0$

History of impaired blood glucose

Yes 5

No 0

Waist circumference

$\mathrm{M}:<94 \mathrm{~cm} \mathrm{~F}:<80 \mathrm{~cm}$

M: 94 - 102 cm F: 80 - $88 \mathrm{~cm}$

M: $>102 \mathrm{~cm} \mathrm{~F}:>88 \mathrm{~cm}$

Body Mass Index

$\begin{array}{cc}<25 \mathrm{~kg} / \mathrm{m}^{2} & 0 \\ 25-30 \mathrm{~kg} / \mathrm{m}^{2} & 1 \\ >30 \mathrm{~kg} / \mathrm{m}^{2} & 3\end{array}$

M: male; F: female; cm: centimeter; kg: kilogram; m: meter. 